\title{
Prolidase Deficiency in Cultured Human Fibroblasts: Biochemical Pathology and Iminodipeptide-Enhanced Growth
}

\author{
MICHAEL DOLENGA AND PETER HECHTMAN \\ Centre for Human Genetics, Department of Biology, McGill University and McGill University-Montreal \\ Children's Hospital Research Institute, Montreal, Quebec, Canada H3H IP3
}

\begin{abstract}
Prolidase deficiency is a rare autosomal recessive disorder characterized by iminodipeptiduria, severe skin ulcers, recurrent infections, and mental retardation. The enzyme prolidase hydrolyzes dipeptides containing C-terminal proline or hydroxyproline. We investigated the metabolic abnormality caused by prolidase deficiency in human cultured skin fibroblasts. These studies were undertaken to test biochemical hypotheses regarding the metabolic origins of the skin lesion occurring in this disease. Our results indicate that prolidase plays a major role in the recycling of dipeptide-bound proline. Control fibroblasts were able to use iminodipeptides in lieu of proline to sustain normal growth, whereas cells homozygous for the prolidase deficiency mutation were not. Proline derived from iminodipeptides diluted incorporation of radiolabeled extracellular proline into cellular protein in normal cells but not in mutant cells. Substitution of a prolidase-free medium for FCS did not affect the growth rate of control cell lines but increased the doubling time of prolidasedeficient cells by $19 \%$ (28\% in the presence of iminodipeptides). Iminodipeptides added to control and mutant cells maintained in serum-free medium showed no adverse effects on protein synthesis. These results are consistent with a mechanism of biochemical pathology in which proline deprivation caused by the enzyme deficit is a primary cause of damage to skin cells. Prolidase regulation by product and substrate was studied. A $44 \%$ decrease in activity was observed in fibroblasts grown for 3 wk in proline-containing medium relative to proline-free medium. However, cells grown in medium in which iminodipeptides replaced proline showed no significant difference in prolidase activity. (Pediatr Res 32: 479-482, 1992)
\end{abstract}

\section{Abbreviations}

PD, prolidase deficiency

MEM, minimal essential medium

TCA, trichloroacetic acid

IDP, iminodipeptide

glypro, glycyl-L-proline

Prolidase defiency (McKusick 26413) is a rare, autosomal recessive disorder characterized by iminodipeptiduria, skin lesions, recurrent infections, and mental retardation (1). The enzyme prolidase (EC 3.4.13.9) is a homodimer with a subunit

Received January 29, 1992; accepted June 4, 1992.

Correspondence: Dr. Peter Hechtman, McGill University-Montreal Children's Hospital Research Institute, 2300 Tupper St., Montreal, Quebec, Canada H3H IP3.

Supported through a grant from the March of Dimes Birth Defects Foundation. molecular mass of $54.3 \mathrm{kD}(2)$ and a requirement for $\mathrm{Mn}^{2+}$ ions. Prolidase is ubiquitously distributed and catalyzes the hydrolysis of C-terminal proline and hydroxyproline-containing dipeptides. The enzyme presumably functions in the degradation of both dietary protein and in the turnover of body protein and is particularly important in collagen catabolism. The gene, PEPD, is encoded on chromosome $19 \mathrm{p} 13.2$ (2). The relationship between the enzymatic and clinical phenotype is unknown, and no form of treatment is presently available for patients with this condition.

We have studied the biochemical pathology of PD using the cultured human skin fibroblast as a model for investigation of the metabolic role of prolidase in skin cells. The principal difficulty in the cultured cell model is the routine use of FCS in the culture medium. Serum contains prolidase, which may prevent or "cure" the expression of the defect in the cultured cell. We have therefore used a serum substitute that is prolidase-free to develop a selective medium in which optimal growth of the cell is dependent upon the expression of the normal allele at the PEPD locus.

We describe the effects on normal and prolidase-deficient mutant cells of 1 ) growth of cells in medium containing prolidase-free serum substitute, 2 ) protein synthesis by confluent cells in serum-free medium, and 3) growth of cells in proline-free medium. Our results support the hypothesis that the function of prolidase is reclamation of proline bound in dipeptidyl linkage for cellular protein synthesis.

\section{MATERIALS AND METHODS}

Prolidase assay. The procedure of Myara et al. (3) was used with the following modifications: enzyme solutions were preincubated with $1 \mathrm{mM} \mathrm{MnCl}{ }_{2}$ overnight to maximize prolidase activity. Glypro (Sigma Chemical Co., St. Louis, MO) was used at a final concentration of $50 \mathrm{mM}$. Proline released by dipeptide hydrolysis was determined by the method of Chinard (4).

Tissue culture. Human fibroblasts were grown in T75 (or T175) culture flasks (Falcon, Mississauga, Ontario, Canada) containing Eagle's MEM (GIBCO, Burlington, Ontario, Canada) supplemented with $10 \%$ FCS, $1 \%$ Ultraser (GIBCO), $1 \%$ ITS, or ITS+ (Collaborative Research, Bedford, MA) serum substitutes. The latter two preparations contain bovine insulin, Fe-saturated transferrin, and the sodium salt of selenous acid. ITS+ contains, in addition, BSA and linoleic acid. For growth experiments, two different MEM products were used. MEM $_{1}$ (GIBCO preparation $410-1500$ ) is the more complete medium, containing aspartate, asparagine, glutamate, serine, and proline, whereas $\mathbf{M E M}_{2}$ (GIBCO preparation 410-1100) is deficient in these amino acids. In addition, $\mathrm{MEM}_{2}$, but not $\mathrm{MEM}_{1}$, contains choline bitartrate. Cells were grown at $37^{\circ} \mathrm{C}$ in $5 \% \mathrm{CO}_{2}$ and were fed every 3 or 4 d.

The normal fibroblast cell lines, $\mathrm{MCH} 39$ and $\mathrm{MCH}$ 70, were 
derived from foreskin explants after circumcision. Prolidasedeficient cell lines were obtained from a 27 -y-old clinically affected female (WG 1625) and a male infant (WG 1077) detected by neonatal screening (5) who remains asymptomatic at the age of $8 \mathrm{y}$. Both individuals had massive iminodipeptiduria. Determination of prolidase sp act in these cell lines are reported in Table 1.

Growth curves. Cell counting was performed after trypsinization using a Coulter counter (Coulter Electronics, Burlington, Ontario, Canada). All reported cell numbers represent a mean of three Petri dishes, each counted in triplicate. Doubling times calculated are during the early log phase of growth.

Protein synthesis. Fibroblasts were grown to confluence in P60 dishes, the medium was removed, and the cell monolayers were washed twice with isotonic PBS. Serum-free medium was then added along with $10 \mu \mathrm{Ci}$ of the radiolabeled amino acid (L-2,3${ }^{3} \mathrm{H}$-proline, $52.0 \mathrm{Ci} / \mathrm{mmol}$; $\mathrm{L}-4,5-{ }^{3} \mathrm{H}$-leucine, $60.0 \mathrm{Ci} / \mathrm{mmol}$; New England Nuclear, Boston, MA). After the labeling period, the medium was removed the cells washed twice with PBS and lysed with a solution of $2.5 \%$ Triton $\mathrm{X}-100$ and $3 \mathrm{M} \mathrm{NaCl}$.

The radioactivity in the TCA-precipitable component of the cell lysate was determined by the method of Mans and Novelli (6). The protein concentration of the lysate was determined by the method of Lowry et al. (7) using crystalline BSA (Sigma) as protein standard.

Uptake of radiolabeled hydroxyproline by fibroblasts. The same procedure as above was employed using hydroxyproline (4-OH-(G)- ${ }^{3} \mathrm{H}$-proline, $5.5 \mathrm{Ci} / \mathrm{mmol}$; New England Nuclear) except that the radioactivity of the total cell lysate itself was determined by scintillation counting without TCA precipitation.

\section{RESULTS}

Commercially available serum substitutes were screened to identify a prolidase-free source of cellular growth and attachment factors. Table 1 records the prolidase activity of FCS and three serum substitutes.

Growth rates of control and PD cells were compared in FCS and ITS or ITS+ containing $\mathrm{MEM}_{1}$. The log-phase doubling times for these growth curves are presented in Table 2. ITS medium significantly increased the doubling time for control cells relative to FCS-containing media, whereas ITS+ medium did not affect the growth characteristics of control cells but did selectively decrease growth of the prolidase-deficient cell lines. These results suggested two hypotheses: 1) IDP substrates accumulating in the absence of prolidase inhibit cell growth or 2) the activity of prolidase is required for optimal cell growth by virtue of its role in reclamation of proline (or other amino acids). Alternatively, the differential response to ITS+ medium may be related to genetic differences between the cell lines other than those occurring at the PEPD locus. The two PD cell lines were used to test the putative antimetabolite activity of IDP substrates

Table 1. Prolidase activity of FCS, serum substitutes, and human fibroblast cell lines

\begin{tabular}{lc}
\multicolumn{2}{c}{ human fibroblast cell lines } \\
\hline \multicolumn{2}{c}{$\begin{array}{c}\text { Prolidase activity } \\
\text { glypro hydrolyzed } / \mathrm{mL} / \mathrm{h})\end{array}$} \\
\hline Serum or substitute & \\
FCS & 8.9 \\
Ultraser G & 47.4 \\
ITS & $<0.1$ \\
ITS+ & $<0.1$ \\
& $(\mu$ mol glypro hydrolyzed $/ \mathrm{mg}$ protein $/ \mathrm{h})$ \\
\cline { 2 - 2 } Cell lines & \\
MCH 39 & \\
MCH 70 & 39.7 \\
WG 1077 & 53.4 \\
WG 1625 & $<0.1$ \\
\end{tabular}

Table 2. Effect of IDP on growth of fibroblasts

\begin{tabular}{llc}
\hline Cell line & \multicolumn{1}{c}{ Medium used } & Doubling time $(\mathrm{h})^{*}$ \\
\hline MCH 39 & MEM $_{1}+10 \%$ FCS & $55.5 \pm 4.3$ \\
MCH 39 & MEM $_{1}+$ ITS & $66.4 \pm 5.9$ \\
MCH 39 & MEM $_{1}$ ITS+ & $57.0 \pm 4.0$ \\
MCH 39 & MEM $_{1}+$ ITS+, + 4 IDP+ & $54.3 \pm 5.1$ \\
WG 1625 & MEM $_{1}+10 \%$ FCS & $85.8 \pm 6.8$ \\
WG 1625 & MEM $_{1}+$ ITS+ & $102.1 \pm 7.3$ \\
WG 1625 & MEM $_{1}+$ ITS+, + 4 IDP+ & $109.6 \pm 8.2$ \\
\hline
\end{tabular}

* Growth curves were performed with three dishes for each time point, and three samples from each dish were counted.

† Five $\mathrm{mM}$ each of glycyl-L-proline, leucyl-L-proline, phenylalanineL-proline, and alanyl-t-proline.

Table 3. Effect of glycl-L-proline on incorporation of leucine and proline into protein

\begin{tabular}{llcc}
\hline & \multicolumn{1}{c}{ Medium } & $\begin{array}{c}\text { Leucine } \\
\text { incorporated } \\
\text { (cpm/ } / \mu \mathrm{g})\end{array}$ & $\begin{array}{c}\text { Proline } \\
\text { incorporated } \\
(\mathrm{cpm} / \mu \mathrm{g})\end{array}$ \\
\hline MCH 39 & $\mathrm{MEM}_{1}$ & $13586 \pm 687$ & $4129 \pm 422$ \\
MCH 39 & $\mathrm{MEM}_{1}+5 \mathrm{mM}$ glypro & $12905 \pm 579$ & $2069 \pm 196$ \\
MCH 70 & $\mathrm{MEM}_{1}$ & $8720 \pm 594$ & $2338 \pm 303$ \\
MCH 70 & $\mathrm{MEM}_{1}+5 \mathrm{mM}$ glypro & $8557 \pm 1316$ & $1725 \pm 242$ \\
WG 1625 & $\mathrm{MEM}_{1}$ & $9298 \pm 1191$ & $1063 \pm 31$ \\
WG 1625 & $\mathrm{MEM}_{1}+5 \mathrm{mM}$ glypro & $10301 \pm 1137$ & $1101 \pm 186$ \\
WG 1077 & MEM $_{1}$ & $5935 \pm 160$ & $3239 \pm 470$ \\
WG 1077 & $\mathrm{MEM}_{1}+5 \mathrm{mM}$ glypro & $6328 \pm 243$ & $3438 \pm 253$ \\
\hline
\end{tabular}

in a culture system in which neither cells nor medium possessed the enzymatic activity required for the hydrolysis of these compounds. As seen in Table 2, the combination of the four IDP did not retard the growth of the control cells but had a small effect on the PD cell lines growing in prolidase-free ITS+ medium.

The effect of IDP on protein synthesis by confluent cells in serum-free medium as determined by following incorporation of both ${ }^{3} \mathrm{H}$-leucine and ${ }^{3} \mathrm{H}$-proline into TCA-precipitable material is shown in Table 3. In none of the cell lines tested did glypro alone or the combination of four IDP (data not shown) decrease the rate of incorporation of leucine into protein, indicating that these dipeptides do not cause inhibition of protein synthesis. The reduction of proline incorporation in the presence of glypro, however, occurred only in the two normal cell lines, although not to the same extent.

The absence of glypro inhibition of leucine incorporation indicates that reduction of proline incorporation cannot be due to protein synthesis inhibition. An alternative site of IDP inhibition of proline incorporation might be the interaction of the IDP substrates and proline at a plasma membrane transport carrier. Inhibition of imino acid transport by IDP was ruled out by measuring the effect of these compounds on the uptake of 4hydroxyproline. This amino acid was used as a transport substrate in lieu of L-proline because the two compounds share a membrane transport carrier (8) but hydroxyproline is not incorporated into protein. These results are shown in Figure 1. The most likely explanation for the observed decrease in proline incorporation by normal fibroblasts in the presence of IDP is the hydrolysis of the IDP by intracellular prolidase and the subsequent dilution of the isotope by the proline produced during hydrolysis.

An alternative hypothesis regarding the role of prolidase is that it functions as a "salvage" enzyme to recover dipeptide-bound proline and make it available for protein synthesis. Experiments were performed to determine whether 1 ) proline in the growth medium is limiting for growth of normal fibroblasts, 2) the activity of prolidase in normal fibroblasts is sufficient to supply the proline requirements of a proline-starved cell, and 3) proli- 


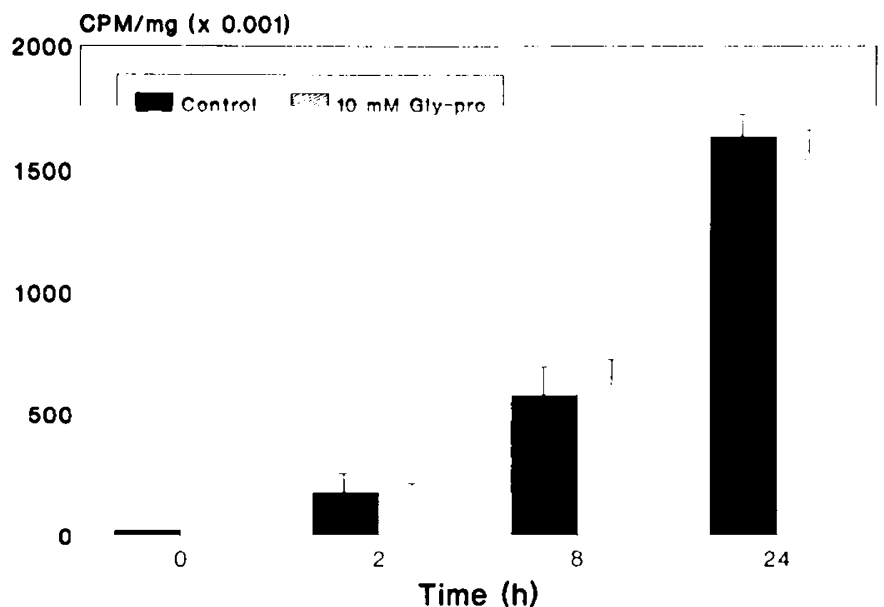

Fig. 1. Uptake of 4-hydroxy-(G)- ${ }^{3} \mathrm{H}$-proline in fibroblasts in the presence $(\square)$ and absence (ש्Z) of glycyl-L-proline.

Table 4. IDP-dependent growth

\begin{tabular}{crrrr}
\hline & \multicolumn{4}{c}{ Doubling times (h)* } \\
\cline { 2 - 5 } Medium & MCH 39 & \multicolumn{1}{c}{ MCH 70 } & WG 1625 & WG 1077 \\
\hline $\mathrm{MEM}_{2}$ & $80.2 \pm 4.1$ & $103.4 \pm 9.3$ & $77.8 \pm 4.7$ & $109.6 \pm 8.7$ \\
$\mathrm{MEM}_{2}+$ Pro 1 mM & $45.8 \pm 3.7$ & $81.3 \pm 8.1$ & $38.9 \pm 2.9$ & $85.2 \pm 7.6$ \\
$\mathrm{MEM}_{2}+$ glypro 10 & $47.0 \pm 5.2$ & $85.6 \pm 6.8$ & $74.2 \pm 5.5$ & $113.8 \pm 9.3$ \\
$\mathrm{mM}$ & & & & \\
$\mathrm{MEM}_{2}+$ Pro 1 mM & $49.0 \pm 4.9$ & $82.3 \pm 7.9$ & $34.3 \pm 3.5$ & $82.9 \pm 7.1$ \\
+ glypro 10 mM & & & & \\
\hline
\end{tabular}

* Growth curves were performed with three dishes for each time point, and three samples from each dish were counted.

dase-deficient cell lines are unable to satisfy proline requirements from IDP precursors.

Table 4 shows the results (expressed as the log-phase doubling times, in h) of a growth experiment where both mutant and normal fibroblasts were grown in proline-deficient $\mathbf{M E M}_{2}$ (see Materials and Methods for description) and in $\mathbf{M E M}_{2}$ to which proline has been added. Doubling times for cell lines in unsupplemented $\mathrm{MEM}_{2}$ are high, indicating slow growth. A comparison of $\mathrm{MCH} 39$ doubling times in $\mathrm{MEM}_{2}$ (Table 4) can be made with the doubling time in the more complete $\mathrm{MEM}_{1}$ (Table 2). Although $\mathrm{MEM}_{2}$ differs from $\mathrm{MEM}_{1}$ by the absence of five amino acids from the former preparation, it is evident from Table 4 that supplementation of $\mathrm{MEM}_{2}$-grown cultures with proline alone can increase the growth by as much as 2 -fold and that the growth rate increase occurs in both control and prolidase-deficient fibroblasts. The $25 \%$ higher growth rate of control cells in $\mathrm{MEM}_{2}$ plus $1 \mathrm{mM}$ proline suggests that proline concentration $(0.1 \mathrm{mM})$ in $\mathrm{MEM}_{1}$ is limiting for cell growth.

The ability to sustain optimal growth when glypro replaces proline, however, is limited to normal genotypes and does not occur in the two prolidase-deficient cell lines. Table 4 shows the doubling times of the four cell lines when both proline and glypro are present in the medium. In this experiment, the doubling times are identical to those in which proline is the sole supplement. This experiment shows that the inability of prolidasedeficient cells to grow optimally in the presence of glypro is due to inability to convert the substrate to proline, not to an inhibition of growth by unhydrolyzed prolidase substrates.

To determine whether prolidase activity in fibroblasts is regulated by product and/or substrate, normal fibroblasts were grown for $21 \mathrm{~d}$ in media containing proline, glypro, and a combination of both. The sp act of cells grown in each condition are presented in Table 5. A control group had no proline or glypro added to the growth medium but contained $0.1 \mathrm{mM}$ proline present in MEM $_{1}$.

The only deviation from the control value occurs when there
Table 5. Regulation of fibroblast prolidase activity

\begin{tabular}{lcr}
\multicolumn{1}{c}{ Medium } & $\begin{array}{c}\text { Prolidase activity } \\
(\mu \mathrm{mol} / \mathrm{mg} / \mathrm{h})\end{array}$ & \multicolumn{1}{c}{$\%$} \\
\hline MEM $_{1}$ - Pro & $56.7 \pm 10.2$ & 100.0 \\
MEM $_{1}+$ Pro 1 mM & $31.8 \pm 7.6$ & 56.1 \\
MEM $_{1}+$ Glypro $5 \mathrm{mM}$ & $58.6 \pm 8.1$ & 103.4 \\
MEM $_{1}+$ Glypro 5 mM + Pro & $53.9 \pm 13.6$ & 95.1 \\
$1 \mathrm{mM}$ & & \\
\hline
\end{tabular}

is an excess of proline $(1 \mathrm{mM})$ in the growth medium causing a decrease in sp act of $50 \%$, suggesting some end product regulation of prolidase. The addition of IDP alone does not enhance prolidase activity. In the presence of proline and substrate, however, no decrease in activity is observed. The results suggest that, at normal MEM, proline concentration, cell growth depends upon maximal expression of the enzyme.

\section{DISCUSSION}

PD is both selective in its site of clinical expression and variable in its severity. Six of 31 patients reported are asymptomatic (1) and two of these are older siblings of severely affected patients $(9,10)$. Because the skin is the most frequently affected tissue clinically, we believed it would be useful to determine whether one of the more easily cultured skin cell types, the fibroblast, would manifest any growth or metabolic abnormality in culture that could be attributed to the enzyme deficiency. A cellular phenotype whose appearance could be subjected to experimental manipulation would be of benefit in the investigation of such questions as: What is the biochemical pathology responsible for the clinical phenotype? What is the biochemical basis for the variable clinical expression both within and between families? Can any experimental evidence be obtained in support of dietary manipulation as a therapeutic strategy for PD?

Previous metabolic studies of PD have used the fibroblast as a model, but the presence of prolidase in the FCS component of growth medium has been ignored (11). Thus, PD cells grown in FCS-containing medium may have their phenotype corrected by extracellular prolidase. This would occur if the excretion of IDP into the medium is a critical event in the development of the cellular phenotype. In the cultured fibroblast, IDP that are produced during protein catabolism are freely diffusible across the plasma membrane. In prolidase-containing medium, the amino acid products of dipeptide hydrolysis can be recycled back to the cell.

The demonstration that proline, which is not an essential amino acid, is limiting for the optimal growth of fibroblasts was an important requirement for clarifying the role of prolidase. The finding that normal fibroblasts are able to use glypro to satisfy their proline requirement demonstrates that prolidase functions in vivo to recycle proline and that the clinical phenotype in PD is likely to be related to a failure to recycle this amino acid. This interpretation is consistent with previous studies showing that a substantial portion of proline incorporated into collagen in rat skin fibroblasts is recycled (12) and that approximately $10 \%$ of newly synthesized cultured fibroblast protein is rapidly degraded even during log-phase growth (13).

This conclusion is not supported, however, by clinical experience with PD patients. In three studies patients did not respond to oral supplementation with proline (14-16), whereas in a fourth study in which patients were reported to have improved clinically the results were not definitive because of the presence of other dietary supplements such as $\mathrm{Mn}$ and large doses of vitamin C (17). It has also been reported that serum levels of proline are within normal limits in PD patients (18).

This study demonstrates that IDP do not act as antimetabolites in fibroblasts. This does not rule out action against another cell type; furthermore, the IDP tested included only four of the most abundantly excreted compounds and not the entire group of 19 
possible IDP. A potential investigative tool that may be useful in clarifying the mechanism underlying the skin phenotype in PD is the pharmacologic agent captopril (D-3-mercapto-2-methylpropanoyl-L-proline) (Merck, Montreal, Canada). Captopril is a common antihypertensive drug that is a structural analog of the IDP cysteinylproline and alanylproline. It is believed to exert antihypertensive effects by competitively inhibiting the carboxypeptidase, angiotensin-converting enzyme (19). This drug also competitively inhibits prolidase in vitro and in vivo (20).

Some individuals using captopril may suffer skin lesions (19) that bear a resemblance to those presenting in prolidase-deficient individuals. This response can be corrected by a reduction in dosage. The mechanism underlying the captopril-induced skin lesions is not well understood, but Wilkin et al. (21) proposed that the lesions are inflammatory responses elicited by the persistence of kinins resulting from the inhibition of kininase II (also a carboxypeptidase) by captopril.

\section{REFERENCES}

1. Phang JM, Scriver CR 1989 Disorders of proline and hydroxyproline metabolism. In: Scriver C, Beaudet A, Sly W, Valle D (eds) The Metabolic Basis of Inherited Disease. McGraw-Hill, New York, pp 577-598

2. Endo F, Tanoue A, Nakai H, Hata A, Indo Y, Titani K, Matsuda I 1989 Primary structure and gene localization of human prolidase. J Biol Chem 264:4476-4481

3. Myara I, Charpentier C, Lemonnier A 1982 Optimal conditions for prolidase assay by proline colorimetric determination: application to iminodipeptiduria. Clin Chim Acta 125:193-20

4. Chinard FP 1952 Photometric estimation of proline and ornithine. J Biol Chem 199:91-95

5. Lemieux B, Auray-Blais C, Giguere R, Shapcott D 1984 Prolidase deficiency: detection of cases by a newborn urinary screening program. J Inherited Metabol Dis 7(suppl):145-147

6. Mans R. Novelli G 1961 Measurement of the incorporation of radioactive amino acids into protein by a filter paper disc method. Arch Biochem Biophys 94:48-53

7. Lowry OH, Rosebrough N, Farr A, Randall R 1951 Protein measurement with the Folin phenol reagent. J Biol Chem 193:265-275

8. Scriver CR, Efron ML, Schafer LA 1964 Renal tubular transport of proline. hydroxyproline and glycine in health and in familial hyperprolinemia. J Clin Invest 43:374-385

9. Isemura M, Hanyu T, Gejyo F, Nakazawa R, Igarashi R, Matsuo S, Ikeda K, Sato Y 1979 Prolidase deficiency with imidodipeptiduria. A familial case with and without clinical symptoms. Clin Chim Acta 93:401-407

10. Umemura S 1978 Studies on a patient with iminodipeptiduria. II. Lack of prolidase activity in blood cells. Physiol Chem Phys Med NMR 10:279-283

11. Chamson A, Voigtlander I, Myara I, Frey J 1989 Collagen biosynthesis anomalies in prolidase deficiency: effect of glycyl-1-proline on the degradation of newly synthesized collagen. Clin Physiol Biochem 7:128-136

12. Jackson SH, Heininger JA 1975 Proline recycling during collagen metabolism as determined by concurrent ${ }^{18} \mathrm{O}_{2}$ and ${ }^{3} \mathrm{H}$ labelling. Biochim Biophys Acta 381:359-367

13. Berg RA, Schwartz ML, Crystal RG 1980 Regulation of the production of secretory proteins: intracellular degradation of newly synthesized "defective" collagen. Proc Natl Acad Sci 77:4746-4750

14. Sheffield H, Schlesinger P, Faull K, Halpern BJ, Schier GM, Cotton RGH, Hammond J, Danks DM 1977 Iminodipeptiduria, skin ulcerations and edema in a boy with prolidase deficiency. J Pediatr 91:578-583

15. Leonia A, Celta T, Tenni R, Pasqualironchetti I, Bertolini F, Guerra D, Dym K, Castellani A 1980 Prolidase deficiency in two sibs with chronic leg ulcerations. Arch Dermatol 123:493-499

16. Charpentier C, Dagbovie K, Lemonnier A, Larregue M, Johnstone RAW 1981 Prolidase deficiency with iminodipeptiduria: biochemical investigations and first results of attempted therapy. J Inherited Metab Dis 1:77-78

17. Pedersen PS, Christensen E, Brandt NJ 1983 Case report: prolidase deficiency. Acta Paediatr Scand 72:785-788

18. Freij BJ, Levy HL, Dudin G, Mutasin D, Deib M, der Kaloustian VM 1984 Clinical and biochemical characteristics of prolidase deficiency in siblings. Am J Med Genet 19:561-57!

19. Vidt DG, Bravo EL, Fouad FM 1982 Drug therapy: captopril. N Engl J Med 306:214-219

20. Ganapathy V, Pashley SJ, Roesel RA, Pashley DH, Leibach FH 1985 Inhibition of rat and human prolidases by captopril. Biochem Pharmacol 34:12871291

21. Wilkin JK, Hammond JJ, Kirkendall WM 1980 The captopril induced eruption. Arch Dermatol 116:902-906 